\section{Muted response to proposals to reform British universities}

\section{London}

Proposals to change the basis of scientific research and teaching in Britain's higher education institutions have not provoked the full-throated outcry that might have been expected. Academics seem in general to accept that decreasing government support means that the present system of a wide spread of scientific research across many institutions, although desirable, is no longer sustainable. It is widely agreed that a greater level of concentration of research is needed, but serious doubts persist about the wisdom of introducing a formally tiered system in the way that is being recommended by the Advisory Board for the Research Councils (ABRC) in a discussion document released last week (see Nature 328, 280; 1987).

ABRC's suggestion is that some institutions should be devoted mainly to undergraduate teaching, others (about 15)

\section{Syrian cosmonaut reaches space station}

\section{London}

THE Soviet Union's first guest-cosmonaut from the non-socialist developing world, the Syrian Mohammad Faris, arrived safely aboard Mir space station last Friday. The flight plan was somewhat unusual; the Soviet space-planners used the relatively new 48-hour trajectory between launch and docking, which, according to deputy flight controller Viktor Blagov, reduces the strain on both crew and ground-services, and also entails minimal expenditure of energy. Also for the first time, the manned transport craft came in to dock with the space station from the side of the astrophysical module.

Faris's programme aboard Mir follows closely the pattern established by previous guest-cosmonauts - a mix of medical, biological and technological work and photography and telemetry of the guest's homeland. In particular, the joint programme includes the production of crystals (gallium arsenide) and a eutectic alloy of aluminium and nickel, to study the

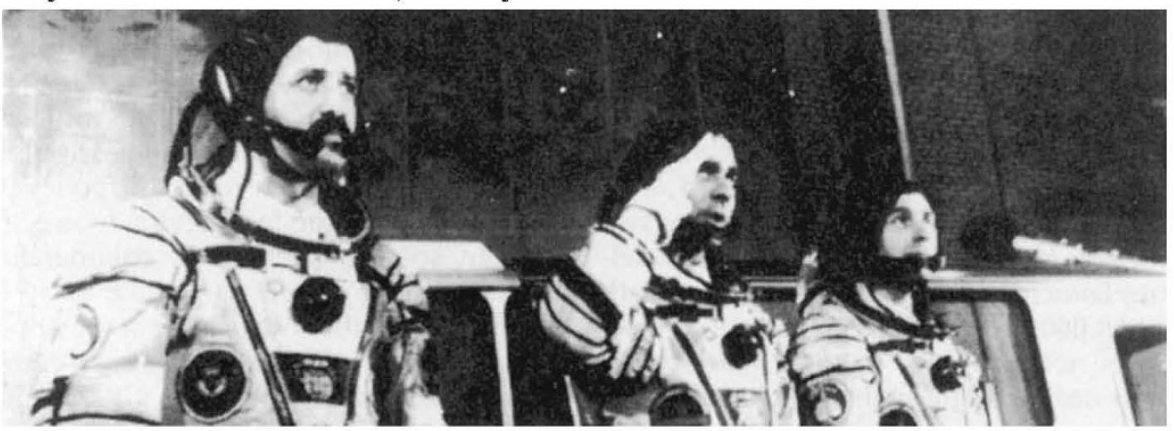

The Soviet-Syrian crew: Faris (left), commander A. Viktorenko and engineer A. Alexandrov. should offer undergraduate and postgraduate teaching and substantial research facilities across the range of fields, and a third category whose teaching and research is across a narrower range of fields.

The main fear expressed by the heads of Britain's universities is that the proposed system would lack flexibility and not be amenable to review: that once categorized, institutions would be unable to 'better' themselves.

The Committee of Vice-Chancellors and Principals (CVCP) is opposed to any formal stratification, although it concedes that the report has much to commend it and that it could have been potentially more damaging. But CVCP is wary of several possible pitfalls, in particular the difficulty of choosing criteria to identify an institution's future status.

Unsurprisingly, it is the smaller universities, with one or perhaps two successful

effect of microgravity on structure. But in one respect, Faris's experiments differ from those of the previous 'guest'. These had to do their experimental work in the Salyut space station itself, where even during designated rest periods, the cosmonauts' movements could create sufficient vibrations to affect the crystallization process. But in the case of Mir, experimental work is not done in the space-station proper, but in one of the specially equipped experimental modules docked with it. As Aleksander Dunaev, head of the new Soviet commercial space agency Glavkosmos explained recently, to carry out a technological experiment, the crew load the furnaces and switch on the appropriate programme, and then undock the module. The latter then remains in independent flight until the experiment is complete, undisturbed by any crew activities. At the end of the experiment, the module is docked again with the station, and the experimental capsules can be withdrawn for return to Earth. Vera Rich ful of the new system. The heads of such institutions argue that a successful department should not be penalized because the institution as a whole is not deemed suitable to be included in one of the research categories. The department should itself be the focus for related work, and a research centre set up around it. Such a system, however, would be unlikely to be able to support the relatively few interdisciplinary research centres that ABRC is proposing.

Whether the suggested system of 'teaching-only' institutions would be able to carry out the sort of research needed to produce high-calibre graduates is another question that is troubling academics.

Not everyone agrees with the ABRC's proposals. Some vice-chancellors say that the present system of selectivity for funds being adopted by the research councils and the University Grants Committee is perfectly adequate, and that, left alone, a naturally differentiating system would evolve. Simon Hadlington

- If proposals to reshape British academic science are to be successfully implemented, a substantial increase in investment in the science base is necessary, the Education Secretary, Kenneth Baker, has been told. In its annual advice to the government on the science budget, the Advisory Board for the Research Councils (ABRC) calls for an extra $£ 103$ million in $1988-89$, rising to $£ 166$ million by 1990-91. The budget is currently $\$ 676$ million. Last year, ABRC requested only an extra $£ 35$ million. The size of the request has cheered the science community, but it remains uneasy about ABRC's proposals for a three-tier classification of higher-education institutions.

In its spending advice, $A B R C$ reiterates the urgency of establishing interdisciplinary university research centres, and proposes that six such centres be created in each of the next three years, which would require additional funds of $£ 90$ million.

Bids for the first such centre, in hightemperature superconductivity, have already been invited (see p.370). ABRC has identified several research programmes with "potential strategic importance" that require additional funds of $\$ 94$ million over the next three years. They include a successor to the Alvey programme of research into information technology, biotechnology, radiological protection, environmental microbiology and ocean flux. Further cash is needed, says ABRC, for re-equipping the best research groups, restructuring of the research councils, support for fellowship schemes and compensation for pay settlements.

Ominously, ABRC, is assuming a "marked reduction" in the United Kingdom's subscription to CERN (The European Organisation for Nuclear Research). A final decision on continuing collaboraation is expected in the autumn. 